\title{
Effects of aging on the suprathreshold responses to vibration
}

\author{
RONALD T. VERRILLO \\ Syracuse University, Syracuse, New York
}

\begin{abstract}
The psychophysical responses to vibration of two age groups (22 or 25 and 66 years) were compared for two tasks using suprathreshold levels of vibrotactile stimulation. At a vibration frequency of $25 \mathrm{~Hz}$, the two age groups gave similar curves of subjective magnitude determined by the method of absolute magnitude estimation. At $250 \mathrm{~Hz}$, the curve of the older group showed no recruitment over low levels of intensity. Instead, their magnitude estimates were depressed over the entire range of intensities. Sensory persistence, measured by a matching procedure, was more marked in the older group.
\end{abstract}

The effect of aging upon the absolute detection threshold for vibration has been reported in a number of publications (Cosh, 1953; Frisina \& Gescheider, 1977; Goldberg \& Lindblom, 1979; Howell, 1947; Laidlaw \& Hamilton, 1937; Mirsky, Futterman, \& Broh-Kahn, 1953; Pearson, 1928; Rosenberg, 1958; Steiness, 1957; Verrillo, 1977, 1979, 1980; Whanger \& Wang, 1974). In general, these studies report a loss of sensitivity as age increases. Verrillo $(1979,1980)$ showed that the loss was frequency selective; between the ages of 10 and 65 years, there was no change in threshold at low frequencies, but there was a substantial loss at higher frequencies. At $250 \mathrm{~Hz}$, sensitivity decreased by approximately $19 \mathrm{~dB}$ between 10 and 65 years of age. The differential loss was interpreted within the duplex theory of mechanoreception (Verrillo, 1968) to indicate that anatomical changes with age within the Pacinian receptor system could account for the loss at $250 \mathrm{~Hz}$, whereas functional characteristics of the non-Pacinian receptor systems could account for the stable threshold at $25 \mathrm{~Hz}$. The loss of sensitivity reported for the higher frequencies is consistent with sensory losses noted in other sense modalities (Corso, 1977; Engen, 1977; Fozzard, Wolf, Bell, McFarland, \& Podolsky, 1977; Kenshalo, 1977).

The effect of aging on responses to suprathreshold stimulation has not been investigated for the vibrotactile systems. The experiments reported here were designed to investigate two aspects of these responses. In the first experiments, the growth of subjective

This research was supported in part by Grant NS09940 from the National Institutes of Health, U.S. Department of Health and Human Services. Portions of this paper were presented at the "Symposium on Age and the Special Senses" in the meeting of the American Physiological Association, Montreal, Canada, September 1-5, 1980. Requests for reprints should be addressed to the author at the Institute for Sensory Research, Syracuse University, Syracuse, New York 13210. magnitude as a function of stimulus intensity was compared in two age groups using a method of magnitude estimation (Stevens, 1957). In the second set of experiments, the phenomenon of sensory persistence was compared in the same age groups using a matching technique.

\section{METHODS AND PROCEDURES}

The apparatus used in these experiments consisted of the appropriate equipment to produce, time, and amplify sinusoidal signals, which were delivered to a vibrator mounted on an adjustable platform beneath a rigid surface (Verrillo, 1968). The contactor was $2.9 \mathrm{~cm}^{2}$ and protruded through a hole in a rigid surface greater by $2 \mathrm{~mm}$ than the diameter of the contractor. The rigid surround prevented surface waves from spreading across the skin. The contactor was pressed into the skin $.5 \mathrm{~mm}$ beyond minimum contact to prevent decoupling during the sinusoidal oscillations. Vibration amplitude was monitored by a precision accelerometer mounted beneath the contactor directly on the moving element of the vibrator. All measurements were made on the thenar eminence of the right hand.

The signals used in the magnitude-estimation experiments were 25- and $250-\mathrm{Hz}$ bursts of $600 \mathrm{msec}$ duration with a $1,400-\mathrm{msec}$ interstimulus time interval. The rise-fall time was $100 \mathrm{msec}$ measured at the half-power point. Following threshold determination by a modified method of limits, the subject was presented with a random series of 10 different intensities ranging from 2 to $50 \mathrm{~dB}$ SL. Three series were presented at each frequency. The subject was instructed to assign to each intensity a number that represented his or her subjective impression of how intense the stimulus was. No standard or modulus was given, in accord with the method of absolute-magnitude estimation (Zwislocki, 1978; Zwislocki \& Goodman, 1980). The signal was repeated until a number was assigned by the subject, at which time it was turned off and the number was recorded. The next intensity was then presented following an alert light to the subject. Typically, a number was assigned after three repetitions of the stimulus. The geometric mean of the second and third runs was taken as the estimate at each intensity level.

The method used to measure sensory persistence was originally developed to measure loudness enhancement (Irwin \& Zwislocki, 1971; Zwislocki \& Ketkar, 1972; Zwislocki, Ketkar, Cannon, \& Nodar, 1974; Zwislocki \& Sokolich, 1974) and was used successfully to measure the phenomenon of enhancement of vibrotactile sensations (Gescheider, Verrillo, Capraro, \& Hamer, 1977; Verrillo 

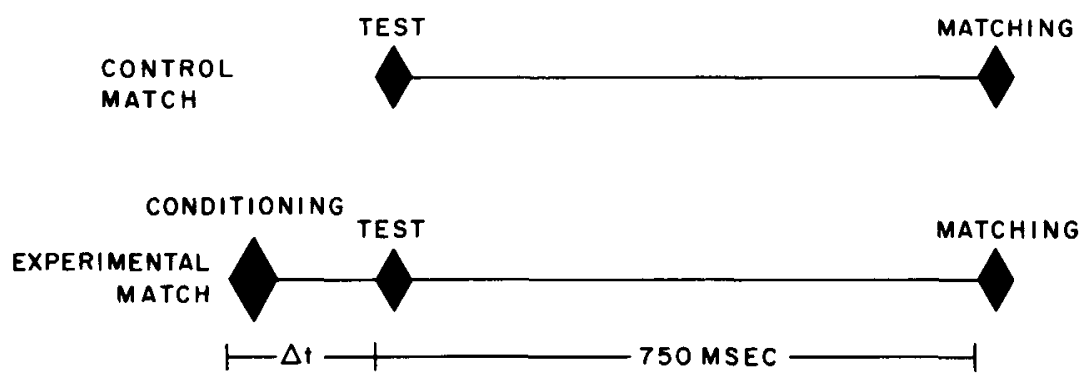

Figure 1. Stimulus paradigm used to measure sensory persistence. See text for explanation.

\& Gescheider, 1975, 1976, 1979b). The stimulus paradigm consists of three short $(20-\mathrm{msec})$ sinusoidal bursts with rise-fall times of $25 \mathrm{msec}$ as measured at the half-power points: the conditioning stimulus, the test stimulus, and the matching stimulus (Figure 1). Following the threshold measurement of the test stimulus alone, it is raised $10 \mathrm{~dB}$ and the subject is then required to make a control match by adjusting the intensity of the matching stimulus to that of the test stimulus. Control matches were made at the start and finish of each testing session, and the results of the two matches were averaged. Adjustment is made by means of an unmarked knob attached to a smooth 120-dB logarithmic attenuator. The time interval between the test and matching stimuli was a constant $750 \mathrm{msec}$. The control match was typically accurate within $\pm 1.0 \mathrm{~dB}$. The intensity of the conditioning stimulus was set an additional $10 \mathrm{~dB}$ above the 10-dB SL of the test stimulus.

Following the control match, the subject was asked to match the intensity of the matching stimulus to that of the test stimulus, but now in the presence of the conditioning stimulus. For the experimental matches, the time interval between the conditioning and test stimuli $(\Delta t)$ was varied randomly from 75 to $500 \mathrm{msec}$. The difference in decibels between the control and experimental matches is a measure of the influence of the conditioning stimulus upon the test stimulus plotted as a function of $\Delta t$. This phenomenon (enhancement) may be viewed as a measure of persistence, within the nervous system, of the conditioning stimulus over the time interval between the conditioning and test stimuli.

Two groups of six subjects each were tested. The subjects were paid volunteers. The elderly group was not institutionalized. One group had a mean age of 25 years (median age 25 years) and a range of 19 to 30 years. The other group ranged in age from 59 to 84 years with a mean of 66 years (median age 67 years). There were three men and three women in each group. Responses to questioning indicated that all of the subjects were in good health, and none reported symptoms of neurological impairment.

\section{RESULTS AND DISCUSSION}

\section{Subjective Magnitude}

Before presenting the results of the present experiments, I should like to point out that data are shown in Figure 2 which indicate that, at $25 \mathrm{~Hz}$, the thresholds of subjects averaging 65 years of age are not dif-

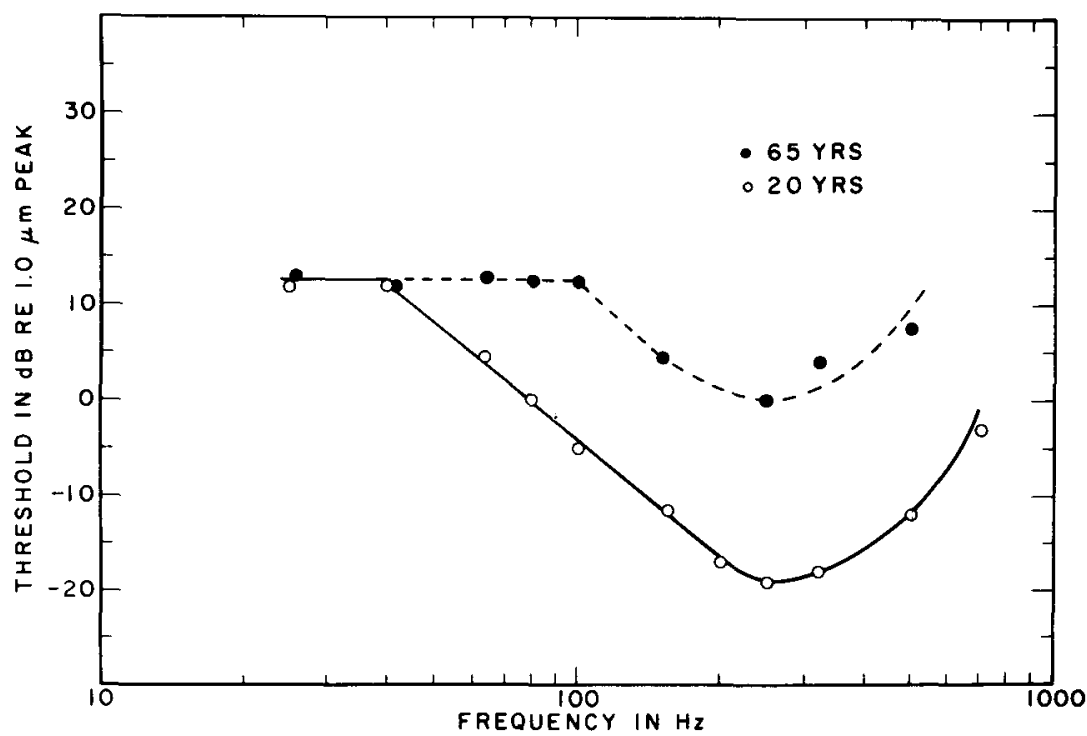

Figare 2. Comparison of absolute thresholds of detection as a function of stimulus frequency for two age groups, 65 years (closed circles) and 20 years (open circles) of age. At $25 \mathrm{~Hz}$, the difference between the groups is insignificant, but at $250 \mathrm{~Hz}$, the older group is approximately $19 \mathrm{~dB}$ less sensitive than the younger group. (Data taken from Verrillo, 1979, 1980) 
ferent from those of a group averaging 20 years of age (Verrillo, 1980). However, the 65-year-old group was approximately $19 \mathrm{~dB}$ less sensitive at a frequency of $250 \mathrm{~Hz}$. Stevens (1968) argued that the decrease of vibrotactile sensitivity at low frequencies was analogous to a loss of sensitivity due to peripheral damage at the cochlea. He reasoned that the growth of subjective sensitivity, therefore, should be more rapid at low frequencies, a phenomenon known as loudness recruitment in persons with damage within the organ of Corti (Fowler, 1928; Hellman, 1981; Hellman \& Zwislocki, 1964; Miskolczy-Fodor, 1964; Pohlman \& Kranz, 1924; Steinberg \& Gardner, 1937; Stevens \& Guirao, 1967; Thalmann, 1965). Loudness recruitment appears as a rapid growth of subjective intensity near threshold, but at higher stimulus intensities the curve approximates the normal loudness function. Retrocochlear damage (neural) results in a downward shift of the entire loudness function, but without recruitment (Davis, 1947; Hirsh, 1952; Thalmanm, 1965). Vibrotactile curves of subjective magnitude are indeed slightly steeper at $25 \mathrm{~Hz}$ than at $250 \mathrm{~Hz}$ (Stevens, 1968; Verrillo, Fraiolo, \& Smith,

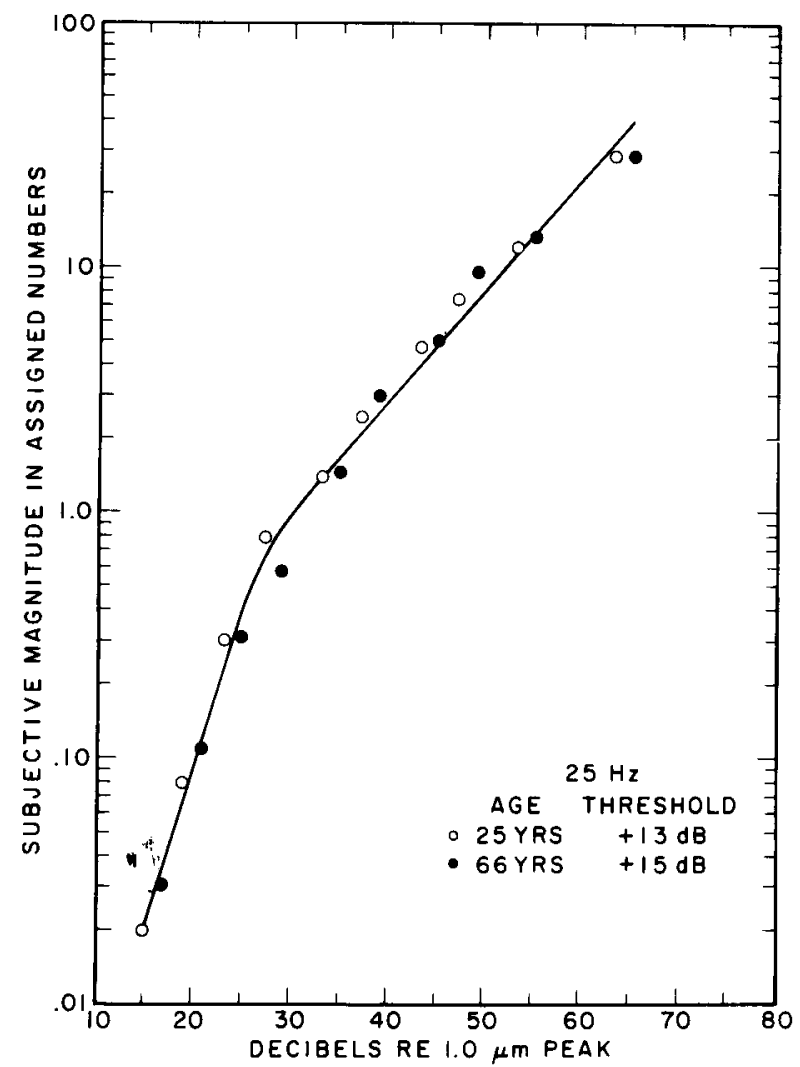

Figure 3. Absolute magnitude estimation (geometric means) of a 25-Hz signal for two age groups, plotted as a function of stimulus intensity in $\mathrm{dB}$ re $1.0 \mathrm{~mm}$ of peal displacement. Both sets of data (25 years, open circles; 66 years, closed circles) could be fitted by the same curve whose slope at the lower intensities is $1.2(r=.96)$ and at the upper intensities, $.46(r=.97)$.

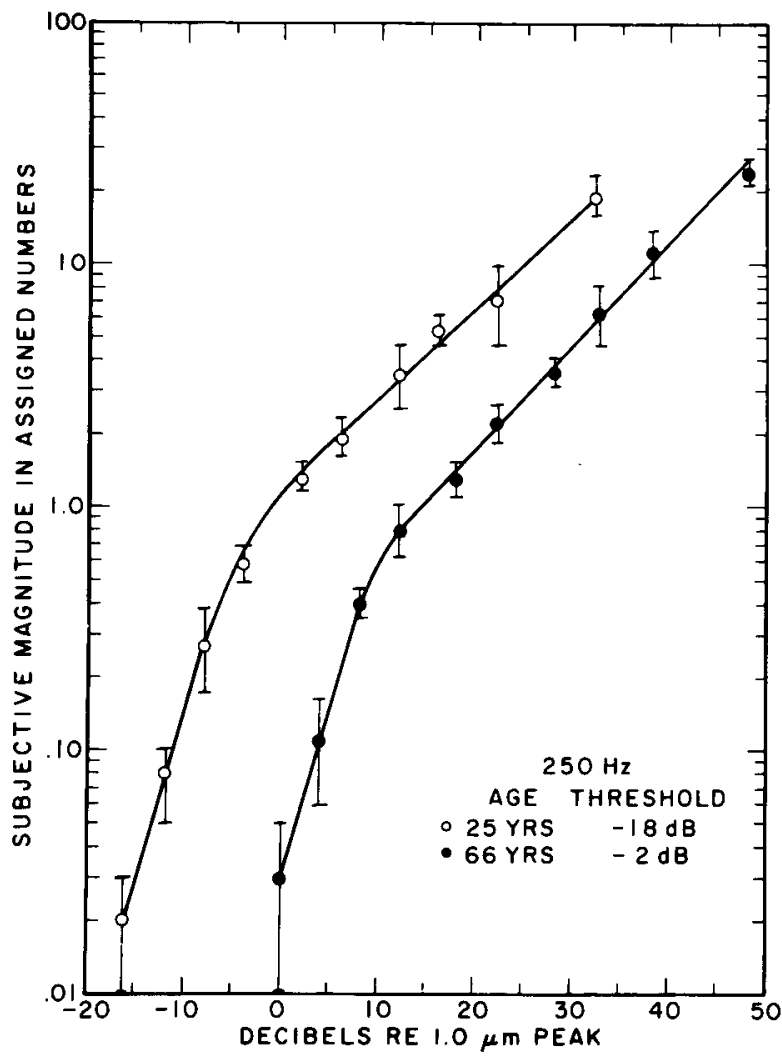

Figure 4. Same as Figure 3, but at a frequency of $250 \mathrm{~Hz}$. The curve for the older group (closed circles) does not show a recruitment effect at intensities near threshold, where the slope is $\mathbf{1 . 2}$ for both groups (66 years, $r=1.0 ; 25$ years, $r=.98$ ). There is a deficit in perceived magnitude at all stimulus intensities in the older group. The slope for the older group at higher intensities is $.43(r=.99)$ and for the younger group, $.38(r=.99)$. Standard error bars are shown.

1969), but the slopes are approximately the same at frequencies above $25 \mathrm{~Hz}$.

Predicting by analogy to the auditory model, we should expect that the similarity of thresholds at $25 \mathrm{~Hz}$ in the two age groups (Figure 2) would result in similar curves of subjective magnitude. The results in Figure 3 do show that, at $25 \mathrm{~Hz}$, the growth of sensation for the 66-year-olds closely approximates that of the younger group. Curves for the two groups, fitted by the method of least squares, were so close that it was possible to draw a single curve to represent both sets of data (upper slope $=.46, r=.97$; lower slope $=1.2, r=.96$ ). Again, by analogy, we should expect that the rather substantial loss in sensitivity at $250 \mathrm{~Hz}$ (Figure 2) for the older group should result in a recruitment effect (receptor changes), in a downward shift of the entire curve of subjective magnitude (neural change), or in both. The results in Figure 4 show that only the downward shift is present. The curve of the 66-year-old group is no steeper near threshold than is that of the 25-year-olds (slope = 1.2, $r=1.0$, both groups). At higher intensities, the 
curve of the older group is shifted downward and is steeper (slope $=.43, r=.99$ ) than the curve of the younger group (slope $=.38, r=.99$ ). Use of the $t$ test showed the difference between the slopes of the two groups to be statistically significant $(p<.01, d f=8)$. The variability in the two age groups was similar. For the 25-Hz data (Figure 3), the standard errors of the mean (Alf \& Grossberg, 1979) for the younger group ranged from .01 to 7.0 ; for the older group, they ranged from .01 to 6.9 . For the $250-\mathrm{Hz}$ data (Figure 4), the standard errors for the younger group ranged from .02 to 3.37 ; for the older group, they ranged from .02 to 2.34 .

Reasonable hypotheses can be developed to explain the findings shown in Figure 4. It has been shown that, at $250 \mathrm{~Hz}$, the psychophysical response to vibration is determined by activation of the Paciniancorpuscle receptor system (Talbot, Darian-Smith, Kornhuber, \& Mountcastle, 1968; Verrillo, 1963, 1966a, 1966b, 1968; Verrillo \& Gescheider, 1979a). The decrease of vibrotactile sensitivity at $250 \mathrm{~Hz}$ that occurs with age may be attributed to several age-related changes within the population of Pacinian corpuscles (Verrillo, 1977, 1979, 1980). As age increases, lamellae are added by apposition to the capsular structure of the corpuscle (Cauna, 1965), resulting in a substantial enlargement of the receptor and possibly a change in the filter characteristic of the capsule (Loewenstein \& Skalak, 1966; Verrillo, 1979, 1980). This change could be associated with the loss of sensitivity at high frequencies (Figure 2), but the loss apparently has no effect on the rate of growth of subjective magnitude at intensities near threshold (Figure 4, $250 \mathrm{~Hz}$ ) for the 66-year-old group. In addition to changes in structure, the population of Pacinian corpuscles reduces with age (Cauna, 1965). Since spatial summation is a characteristic of this system and not of the non-Pacinian system (Verrillo, 1963, 1966c), the reduction in number also may account for the lowered sensitivity at $250 \mathrm{~Hz}$ as well as the shift in the entire subjective-magnitude curve (Figure 4) of the 66-yearold group. The similarity of slope at the lower intensities is consistent with Zwislocki's (1974) hypothesis that, near threshold, the growth of the subjective magnitude is proportional to the responses of individual nerve fibers and that, at higher intensities, it is more closely related to the activity of the entire nerve bundle (Hellman \& Hellman, 1975).

The steeper slope at higher intensities for the older group is also consistent with the finding that, when measurements are made at different sites on the body having different densities of corpuscles, the slopes of the curves vary inversely with the receptor density (Verrillo \& Chamberlain, 1972). Furthermore, when estimates are made using different contactor sizes, the smaller contactor, stimulating fewer receptors, results in a steeper curve of subjective magnitude
(Verrillo, 1974). These results and those of the present study suggest that the position and slope of the curve for the older group relative to the younger group are linked to the reduction in the number of Pacinian corpuscles that occurs with age.

Returning briefly to the changes with age that occur in hearing, in an older population both recruitment near threshold and a reduction of loudness at higher stimulus intensities may be measured and have been associated with a mixture of degenerative changes in the organ of Corti and with losses within the retrocochlear neural chain (Goetzinger, Proud, Dirks, \& Embry, 1961; Hansen \& Reske-Nielsen, 1965; Schuknecht, 1967; Schuknecht \& Igarashi, 1964). We cannot, at the present time, identify with certainty the neural mechanisms responsible for the psychophysical changes in vibrotactile threshold and in subjective magnitude (Figures 2 and 4 ) that occur with age, but they appear to be analogous only to the retrocochlear changes that occur in the auditory system. There seems to be no parallel to the changes that occur within the organ of Corti and the consequent recruitment phenomenon.

\section{Sensory Persistence}

Sensory persistence occurs when a sensation is prolonged psychologically for some time after the offset of the physical stimulus. (For a review and analysis of visible persistence, see Botwinick, 1978, and Coltheart, 1980). Coltheart proposes that persistence of visible stimuli depends on prolonged activity both at the level of the receptor and at stages along the visual pathways. The phenomenon has been investigated using a wide variety of methods. It has been reported, not only in vision, although the preponderance of the literature concerns that modality, but also in hearing and touch (Coltheart, 1980). Visual persistence lasts longer in older subjects (Amberson, Atkeson, Pollack, \& Malatesta, 1979; Brozek \& Keys, 1945; Kline \& Birren, 1975; Kline \& Szafran, 1975; McFarland, Warren, \& Karis, 1958; Misiack, 1951). Mundy-Castle (1953) found that the EEG response to photic stimuli is prolonged as age increases.

A phenomenon closely related to persistence is enhancement, in which a brief stimulus has a measurable effect upon another stimulus that closely follows it in time. Sensory persistence and enhancement may be related by the same or similar underlying neural mechanisms, so it seems reasonable that the same method is used for measuring either phenomenon.

In the present experiments, two groups of subjects, whose mean ages were 22 and 66 years, were tested. There were three men and three women in each group. The subjects were tested by the method described above, using the stimulus paradigm shown in Figure 1. In one experiment, $300 \mathrm{~Hz}$ was used for the conditioning, test, and matching stimuli; in another, 
$25 \mathrm{~Hz}$ was used for all three stimuli. The subjects were tested three times at each frequency, and the results were averaged over the three runs.

The results shown in Figure 5 are for both 25 and $300 \mathrm{~Hz}$ and are compared with the curve of the group whose mean age was 22 years. The data for the 25 and $300-\mathrm{Hz}$ conditions for the younger group were so similar that a single curve could be drawn through both sets of data points. The variability in the two age groups was very close. For the $300-\mathrm{Hz}$ data (Figure 5), the standard errors of the mean for the younger group ranged from .11 to $.34 \mathrm{~dB}$ and for the older group ranged from .14 to $.39 \mathrm{~dB}$. For the $25-\mathrm{Hz}$ data, the standard errors for the younger group ranged from .06 to .32 and for the older group from .07 to .27 .

The results at both frequencies indicated that the conditioning stimulus had a more profound effect upon the test stimulus at all time intervals for the 66-year-old group than it did for the 22-year-old group. This may be interpreted as a longer persistence of the effect of the conditioning stimulus upon the perceived intensity (enhancement) of the test stimulus. Note that the enhancement drops to an insignificant level in the younger group when $\Delta t$ approaches $500 \mathrm{msec}$, whereas in the older group the

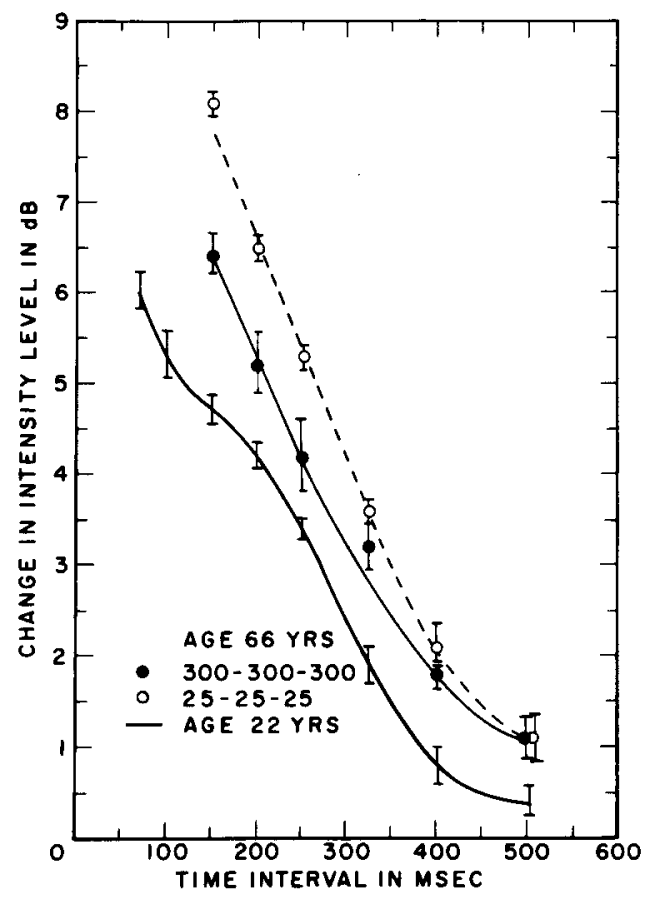

Figure 5. Effect in decibels of the conditioning stimulus on the subjective intensity of the test stimulus, plotted as a function of the interstimulus time interval ( $\Delta t)$. There was no frequency difference in the younger group, so their data are represented by a single, heavy, solid line. Measurements at two frequencies are shown for the older group $(25 \mathrm{~Hz}$, open circles; $300 \mathrm{~Hz}$, closed circles). Standard error bars are shown. elevation of perceived intensity is still above $1.0 \mathrm{~dB}$. The reduction of the enhancement effect to approximately $.5 \mathrm{~dB}$ in the older group did not occur until $\Delta$ t was set at $600 \mathrm{msec}$ (data point not shown). At short time intervals, it should be noted that no data points are shown at $\Delta t=75$ and $100 \mathrm{msec}$. This is because five of the six older subjects could not perceive two stimuli (conditioning and test) at time intervals less than approximately $150 \mathrm{msec}$, whereas the younger group had no difficulty in making this discrimination. We have not systematically studied the minimum perceivable interval between two pulses in different age groups, but this result is consistent with the finding that temporal resolution of somesthetic stimuli declines with age, indicating an increase of persistence (Axelrod, Thompson, \& Cohen, 1968).

It should be pointed out that when this experiment was performed using $25 \mathrm{~Hz}$ for the conditioning stimulus, with the test and matching stimuli set at $300 \mathrm{~Hz}$, there was no enhancement (Verrillo \& Gescheider, 1975, 1976). This would indicate that when Pacinian and non-Pacinian channels are separated at the periphery, interactions between the two systems do not occur, although there is a narrow band of frequencies at which the systems appear to overlap (Gescheider et al., 1977). In the 66-year-old group there was no effect when the combination 25-300-300 Hz was used for the three stimuli (data points not shown). Thus, for both age groups, enhancement (persistence) effects do not appear to cross between channels.

A major difference occurs in the data of the older group (Figure 5) that does not appear in the results obtained with younger subjects. At time intervals between 150 and $200 \mathrm{msec}$, the older group shows markedly greater enhancement at $25 \mathrm{~Hz}$ than at $300 \mathrm{~Hz}$, a result that indicates a longer persistence effect within the non-Pacinian system. The younger group showed no such effect of frequency. This result complements the finding in vision that discrimination of low spatial frequencies is more affected by aging than that of high spatial frequencies (Sekuler, Hutman, \& Owsley, 1980). It is generally accepted that the enhancement effect is most probably due to central rather than peripheral neural processing (Elmasian, Galambos, \& Bernheim, 1980; Galambos, Bauer, Picton, Squires, \& Squires, 1972). Loudness enhancement could not be detected electrophysiologically at the auditory nerve of cats (Bauer \& Galambos, 1975), and the EEG recordings at the level of the brainstem in man revealed no effects for auditory stimuli (Bauer, Elmasian, \& Galambos, 1975). Thus, the mechanism for enhancement probably is the result of information processing at higher levels of the CNS.

It is not possible at the present time to specify what changes occur with age within the nervous system that could account for these results. There is evidence 
that cells receiving inputs from Pacinian and nonPacinian mechanoreceptors are correlated with specific areas (Paul, Goodman, \& Merzenich, 1972; Paul, Merzenich, \& Goodman, 1972), as well as with the cytoarchitecture of somatosensory areas I and II (Bennett, Ferrington, \& Rowe, 1980; Ferrington \& Rowe, 1980; Hyvărinen \& Poranen, 1978), but anatomical differentiation is not in itself sufficient to explain psychophysical results. Evidence of functional differentiation is shown by deficits in specific discrimination tasks provided by selective ablation of sites in the somatosensory cortex (Randolph \& Semmes, 1974). Coupled with these findings is the evidence of extensive changes in central neurons that occur with age (Bondareff, 1977), although the functional significance of many of these changes is not certain.

Peripheral changes are known to occur within transmission neurons and nerve bundles, and at the receptor. The increase in size and the reduction in number of Pacinian corpuscles (Cauna, 1965) have been mentioned above. There are also, with age, changes in morphology and a reduction in the number of Meissner's corpuscles (Bolton, Winkelmann, \& Dyck, 1966; Cauna, 1965), one of the non-Pacinian receptors thought to be responsible for the lowfrequency threshold response. These changes would not be expected to affect the threshold (Figure 2) or the growth of sensation (Figure 3) at $25 \mathrm{~Hz}$, since the non-Pacinian system does not summate energy over space (Verrillo, 1963, 1966c). Although Cauna (1965) reports that both Pacinian and Meissner's corpuscles decline in number with age, he does not indicate if there is a differential loss between the two populations. It is not difficult to relate these anatomical changes with the psychophysical results at threshold (see Verrillo, 1969, 1980) and at suprathreshold levels (discussed above), but a change in the filter characteristics of the Pacinian corpuscle and a reduction in the number of Pacinian and Meissner's corpuscles do not appear to account easily for the frequency difference in older subjects shown in Figure 5.

The changes in neural structure and chemistry that occur with age are considerable in both the peripheral and central nervous systems, but there is insufficient correlative evidence to associate these changes with certainty to functional changes measured psychophysically. They do, however, suggest possible neural mechanisms for these changes.

\section{REFERENCES}

Alf, E. F., \& Grossbeng, J. M. The geometric mean: Confidence limits and significance tests. Perception \& Psychophysics, $1979,26,419-421$.

Amberson, J. I., Atkeson, B. M., Pollack, R. H., \& Malatesta, V. J. Age differences in dark-interval threshold across the life span. Experimental Aging Research, 1979, 5, 423-433.
Axelnod, S., Thompson, L. W., \& Cohen, L. D. Effects of senescence on temporal resolution of somesthetic stimuli presented to one hand or both. Journal of Gerontology, 1968, 23, 191-195.

Bauer, J. W., Elmasian, R., \& Galambos, R. Loudness enhancement in man: I. Brainstem evoked response correlates. Journal of the Acoustical Society of America, 1975, 57, 165-171.

Bauer, J. W., \& Galambos, R. Evoked potentials in cat auditory nerves: Suppression by prior tonal stimulation. Perception \& Psychophysics, 1975, 17, 43-47.

Bennett, R. E., Ferrington, D. G., \& Rowe, M. Tactile neuron classes within second somatosensory area (SII) of cat cerebral cortex. Journal of Neurophysiology, 1980, 43, 292-309.

Bolton, C. F., Winkelmann, R. K., \& Dyck, P. J. A quantitative study of Meissner's corpuscles in man. Neurology, 1966, 16, 1-9.

Bondareff, W. The neural basis of aging. In J. E. Birren \& K. W. Schaie (Eds.), Handbook of the psychology of aging. New York: Van Nostrand Reinhold, 1977.

Botwinick, J. Aging and behavior (2nd ed.). New York: Springer, 1978.

Brozek, J., \& KEYs, A. Changes in flicker-fusion frequency with age. Journal of Consulting Psychology, 1945, 9, 87-90.

Cauna, N. The effects of aging on the receptor organs of the human dermis. In W. Montagna (Ed.), Advances in biology of skin-Aging (Vol. 6). New York: Pergamon, 1965.

Coltheart, M. Iconic memory and visible persistence. Perception \& Psychophysics, 1980, 27, 183-228.

Corso, J. F. Auditory perception and communication. In J. E. Birren \& K. W. Schaie (Eds.), Handbook of the psychology of aging. New York: Van Nostrand Reinhold, 1977.

Cosh, J. A. Studies in the nature of vibration sense. Clinical Science, 1953, 12, 131-150.

Davis, H. Hearing and deafness. New York: Rinehart, 1947.

Elmasian, R., Galambos, R., \& Bernheim, A., Jr. Loudness enhancement and decrement in four paradigms. Journal of the Acoustical Society of America, 1980, 68, 601-607.

ENGEN, T. Taste and smell. In J. E. Birren \& K. W. Schaie (Eds.), Handbook of the psychology of aging. New York: Van Nostrand Reinhold, 1977.

Ferrington, D. G., \& Rowe, M. Differential contributions to coding of cutaneous vibratory information by cortical somatosensory areas I and II. Journal of Neurophysiology, 1980, 43, 310-331.

Fowler, E. P. Marked deafened areas in normal ears. Archives of Otolaryngology, 1928, 8, 151-155.

Fozzard, J. L., Wolf, E., Bell, B., McFarland, R. A., \& Podolsky, S. Visual perception and communication. In J. E. Birren \& K. W. Schaie (Eds.), Handbook of the psychology of aging. New York: Van Nostrand Reinhold, 1977.

Frisina, R. D., \& Gescheider, G. A. Comparison of child and adult vibrotactile thresholds as a function of frequency and duration. Perception \& Psychophysics, 1977, 22, 100-103.

Galameos, R., Bauer, J., Picton, T., Squires, K., \& Squires, N. Loudness enhancement following contralateral stimulation. Journal of the Acoustical Society of America, $1972,52,1127-1130$.

Gescheider, G. A., Verrillo, R. T., Capraro, A. J., \& HAMER, R. D. Enhancement of vibrotactile sensation magnitude and predictions from the duplex model of mechanoreception. Sensory Processes, 1977, 1, 187-203.

Goetzinger, C., Proud, G., Dirks, D., \& Embrey, J. A study of hearing in advanced age. Archives of Otolaryngology, 1961, 73, 662-674.

Goldberg, J. M., \& Lindblom, U. Standardized method of determining vibratory perception thresholds for diagnosis and screening in neurological investigation. Journal of Neurology, Neurosurgery, and Psychiatry, 1979, 42, 793-803.

Hansen, C. C., \& Reske-Nielsen, E. Pathological studies in presbyacusis. Archives of Otolaryngology, 1965, 82, 115-132. 
Hellman, R. P. Stability of individual loudness functions obtained by magnitude estimation and production. Perception \& Psychophysics, 1981, 29, 63-70.

Hellman, W. S., \& Hellman, R. P. Relation of the loudness function to the intensity characteristic of the ear. Journal of the Acoustical Society of America, 1975, 57, 188-192.

Hellman, R. P., \& Zwislocki, J. Loudness function of a 1,000cps tone in the presence of a masking noise. Journal of the Acoustical Society of America, 1964, 36, 1618-1627.

Hirsh, I. J. The measurement of hearing. New York: McGrawHill, 1952.

HowELL, T. H. Senile deterioration of the central nervous system. A clinical study. British Medical Journal, 1947, 1, 56-58.

Hyvärinen, J., \& Poranen, A. Receptive field integration and submodality convergence in the hand area of the post-central gyrus of the adult monkey. Journal of Physiology, 1978, 283, 539-556.

IRwiN, R. J., \& Zwislocki, J. J. Loudness effects in pairs of tone bursts. Perception \& Psychophysics, 1971, 10, 189-192.

Kenshalo, D. R. Age changes in touch, vibration, temperature, kinesthesis, and pain. In J. E. Birren \& K. W. Schaie (Eds.), Handbook of the psychology of aging. New York: Van Nostrand Reinhold, 1977.

Kline, D. W., \& Birhen, J. E. Age differences in backward dichoptic masking. Experimental Aging Research, 1975, 1, 17-25.

KuINe, D. W., \& Szafran, J. Age differences in backward monoptic visual noise masking. Journal of Gerontology, 1975, 30, 307-311.

Laidlaw, R. W., \& Hamilton, M. A. Thresholds of vibratory sensibility as determined by the pallesthesiometer. Bulletin of the Neurological Institute, New York, 1937, 6, 494-503.

Loewenstein, W. R., \& Skalak, R. Mechanical transmission in a Pacinian corpuscle: An analysis and a theory. Journal of Physiology (London), 1966, 182, 346-378.

McFarland, R., Warren, A. B., \& Karis, C. Alterations in critical flicker frequency as a function of age and dark-light ratio. Journal of Experimental Psychology, 1958, 56, 529-538.

Mirsky, I. A., Futterman, P., \& Broh-Kahn, R. H. The quantitative measurement of vibratory perception in subjects with and without diabetes mellitus. Journal of Laboratory and Clinical Medicine, 1953, 41, 221-235.

Misinck, $H$. The decrease in critical flicker with age. Science, 1951, 113, 551-552.

Miskolczy-Fodon, F. Relation between loudness and duration of tonal pulses. III. Response in cases of abnormal loudness. Journal of the Acoustical Society of America, 1964, 36, 1618-1627.

Mundy-Castre, A. C. An analysis of central response to photic stimulation in normal adults. Electroencephalography \& Clinical Neurophysiology, 1953, 5, 1-22.

Paul, R. L., Goodman, H., \& Menzenich, M. Alterations in mechanoreceptor input to Brodmann's areas 1 and 3 of the postcentral hand area of Macaca mulatta after nerve section and regeneration. Brain Research, 1972, 39, 1-19.

Paul, R. L., Merzenich, M., \& Goodman, H. Representation of slowly and rapidly adapting mechanoreceptors of the hand in Brodmann's areas 3 and 1 of Macaca mulatta. Brain, 1972, 36, 229-249.

Pearson, G. H. J. Effect of age on vibratory sensibility. Archives of Neurology and Psychiatry, 1928, 20, 482-496.

Pohlman, A. G., \& Kranz, F. W. Binaural minimum audition in a subject with ranges of deficient acuity. Procedures of the Society for Experimental Biology, 1924, 21, 335.

Randolph, M., \& Semmes, J. Behavioral consequences of selective subtotal ablations in the postcentral gyrus of Macaca mulatta. Brain, 1974, 70, 55-70.

Rosenberg, G. Effect of age on peripheral vibratory perception. Journal of the American Geriatric Society, 1958, 6, 471-481.

Schuknecht, H. F. The effect of aging on the cochlea. In A. B.
Graham (Ed.), Sensorineural hearing processes and disorders. Boston: Little, Brown, 1967.

Schuknecht, H. F., \& Igarashi, M. Pathology of slowly progressive sensorineural deafness. Transactions of the American Academy of Ophthalmology and Otolaryngology, 1964, 68, 222-242.

Sexuler, R., Hutman, L. P., \& Owsley, C. J. Human aging and spatial vision. Science, 1980, 209, $1255-1256$.

Ste inberg, J. C., \& Gardner, M. B. The dependence of hearing impairment on sound intensity. Journal of the Acoustical Society of America, 1937, 9, 11-23.

Steiness, I. Vibratory perception in normal subjects. Acta Medica Scandinavica, 1957, 158, 315-325.

Stevens, S. S. On the psychophysical law. Psychological Review, 1957, 64, 153-181.

Stevens, S. S. Tactile vibration: Change of exponent with frequency. Perception \& Psychophysics, 1968, 3, 223-228.

Stevens, S. S., \& Guirao, M. Loudness functions under inhibition. Perception \& Psychophysics, 1967, 2, 459-465.

Talbot, W. H., Darian-Smith, I., Kornhuber, H. H., \& Mountcastle, V. B. The sense of flutter-vibration: Comparison of the human capacity with response patterns of mechanoreceptive afferents from the monkey hand. Journal of Neurophysiology, 1968, 31, 301-334.

Thalmann, $\boldsymbol{R}$. Cross-modality matching in the study of abnormal loudness functions. Laryngoscope, 1965, 75, 1708-1726.

VERriLlo, R. T. Effect of contactor area on the vibrotactile threshold. Journal of the Acoustical Society of America, 1963 , 35, 1962-1966.

VerhILLO, R. T. Vibrotactile sensitivity and the frequency response of the Pacinian corpuscle. Psychonomic Science, 1966, 4, 135-163. (a)

VerRILlo, R. T. Specificity of a cutaneous receptor. Perception \& Psychophysics, 1966, 1, 149-153. (b)

VERRILLo, R. T. Effect of spatial parameters on the vibrotactile threshold. Journal of Experimental Psychology, 1966, 71, 570-575. (c)

VERRILLO, R. T. A duplex mechanism of mechanoreception. In D. R. Kenshalo (Ed.), The skin senses. Springfield, Ill: Thomas, 1968.

VerriLlo, R. T. Vibrotactile intensity scaling at several body sites. In F. A. Geldard (Ed.), Cutaneous communication systems and devices. Austin, Tex: Psychonomic Society, 1974.

VERRILLo, R. T. Comparison of child and adult vibrotactile thresholds. Bulletin of the Psychonomic Society, 1977, 9, 197-200.

Verrillo, R. T. Change in vibrotactile thresholds as a function of age. Sensory Processes, 1979, 3, 49-59.

Verrillo, R. T. Age related changes in the sensitivity to vibration. Journal of Gerontology, 1980, 35, 185-193.

Verrillo, R. T., \& Chamberlain, S. C. The effect of neural density and contactor surround on vibrotactile sensation magnitude. Perception \& Psychophysics, 1972, 11, 117-120.

Verhillo, R. T., Fraioli, A. J., \& Smith, R. L. Sensation magnitude of vibrotactile stimuli. Perception \& Psychophysics, 1969, 6, 366-372.

Verrillo, R. T., \& Gescheider, G. A. Enhancement and summation in the perception of two successive vibrotactile stimuli. Perception \& Psychophysics, 1975, 18, 128-136.

Verrillo, R. T., \& Gescheider, G. A. Effect of double ipsilateral stimulation on vibrotactile sensation magnitude. Sensory Processes, 1976, 1, 127-137.

Verrillo, R. T., \& Gescheider, G. A. Psychophysical measurements of enhancement, suppression, and surface-gradient effects in vibration. In D. R. Kenshalo (Ed.), Sensory functions of the skin of humans. New York: Plenum, 1979. (a)

Verhillo, R. T., \& Gescheider, G. A. Backward enhancement and suppression of vibrotactile sensation. Sensory Processes, $1979,3,249-260$. (b) 
Whanger, A. D., \& Wang, H. S. Clinical correlates of the vibratory sense in elderly psychiatric patients. Journal of Gerontology, 1974, 29, 39-45.

Zwislocki, J. J. A power function for sensory receptors. In H. R. Moskowitz, B. Scharf, \& J. C. Stevens (Eds.), Sensation and measurement. Dordrecht: Reidel, 1974.

Zwistocki, J. J. Absolute sealing. Journal of the Acoustical Society of America, 1978, 63, S16(A).

Zwislocki, J. J., \& Goodman, D. A. Absolute scaling of sensory magnitudes-a validation. Perception \& Psychophysics, $1980,28,28-38$

ZWISLOCKI, J. J., \& KetKaR, I. Loudness enhancement and summation in pairs of short sound bursts. Journal of the Acoustical Society of America, 1972, 51, 140(A).

Zwislocki, J. J., KetKar, I., Cannon, M. W., \& Nodar, R. H. Loudness enhancement and summation in pairs of short sound bursts. Perception \& Psychophysics, 1974, 16, 91-100.

Zwislocki, J. J., \& Sokolich, W. G. On loudness enhancement of a tone burst by a preceding tone burst. Perception \& Psychophysics, 1974, 16, 87-90.

(Manuscript received March 8, 1982; accepted for publication March 11, 1982.) 